\title{
Research Status of International Intelligence Education
}

\author{
Jiawei $\mathrm{Li}^{1, *}$ \\ ${ }^{1}$ School of Marxism, Zhejiang University, Hangzhou, Zhejiang 310023, China \\ ${ }^{*}$ Corresponding author. Email: lijiaweiea@163.com
}

\begin{abstract}
The vigorous development of artificial intelligence continues to promote the penetration of technology in the field of education. Countries around the world are constantly setting off a wave of research on intelligence education. On the basis of sorting out the concepts of intelligence education, this article systematically reviews the research status of international intelligence education, analyzes highly-cited international journals, leading countries and scientific research institutions in the field of international intelligence education, reveals the research map in the field of international intelligence education, makes an atlas analysis of research keywords, and summarizes the fields and research hotspots of international intelligence education, so as to provide some reference for the research and development of China's intelligence education.
\end{abstract}

\section{Keywords: intelligence education, research status, research hotspot}

\section{INTRODUCTION}

Since the concept of "Artificial Intelligence" was proposed in 1956, it has set off the first wave, with symbolic reasoning and machine reasoning as the primary research priorities. Since 1976, speech recognition, speech translation and the fifth generation robot in Japan have promoted the second wave of AI development. Today, with the breakthrough of deep learning technology and image recognition technology in the ImageNet competition, and the continuous development of natural language processing, data mining, and deep learning technology, artificial intelligence has achieved a leap forward development, and the third wave of artificial intelligence is emerging and continues to penetrate all aspects of life (Liu Dejian, Du Jing, Jiang Nan \& Huang Ronghuai, 2018). The same is true in education. Countries around the world are promoting the development of artificial intelligence in the field of education with different policy orientations, and have initiated extensive research and discussion on intelligence education.

\section{DEFINITION OF INTELLIGENCE EDUCATION CONCEPT}

From the Internet of Things to big data and then to artificial intelligence, China's artificial intelligence policy has undergone continuous evolution. The State Council wrote "Intelligence Education" in the "Development Planning of New Generation Artificial Intelligence" in July 2017. This plan proposed to "use intelligent technology to accelerate the reform of talent cultivation and teaching methods and build a new education system that includes intelligent learning and interactive learning". In April 2018, the Ministry of Education issued the "Innovative Action Plan for Artificial Intelligence in Colleges and Universities", stating that "it is necessary to promote the demonstration of intelligence education applications, accelerate the deep integration and innovative development of artificial intelligence and education, study the development strategy and standard planning of intelligence education, explore the integration path and method of artificial intelligence technology, and comprehensively promote the modernization of education." It can be seen that the state has established the height and positioning of "intelligence education" at the policy level. At the same time, it is proposed by the academic circle that for the development of educational informatization 2.0, intelligence education is the implementation way and the navigation mark (Zhu Zhiting, 2018). Artificial intelligence will have significant impacts on human education and learning methods (Jia Jiyou, 2018).

The idea of intelligence education originated from the thinking of philosophers, aiming to help people to recognize and awaken the "intelligence" of human beings (Krishnamurti, 2004). It is typical of "children's intelligence education theory" of Marlen and "intelligence balance theory" of Stemberg (2001). The emergence of "intelligence education" stems from the development of cognitive computing, learning analysis, perceptual analysis and other emerging intelligent technologies, and the "intelligence education" aims to provide more opportunities for the reform and innovation of education. On the research of "intelligence education", Chinese scholars mainly focus on the "in-depth application of intelligent technology in education and teaching" and "research on taking 
artificial intelligence technology as teaching content" (Liang Yingli \& Liu Chen, 2018; Liu Jiande, Du Jing, Jiang Nan \& Huang Ronghuai, 2018). Zhu Zhiting proposed that intelligence education should focus on improving the full intelligence level of all kinds of talents. Therefore, he proposed the third connotation of intelligence education, namely, the "education to promote intelligent development" (Zhu Zhiting, 2018). Liu Kai and others proposed to divide intelligence education into four basic research issues from the perspective of general artificial intelligence: "human learning, human education, machine learning and machine education" (Liu Kai, Hu Xiangen, Ma Yuhui, Nadi \& Zhang Yuhua, 2018). Zhang Jinbao and others put forward the promotion of core value proposition of intelligence education, the cultivation of key thinking mode and the construction of ontology knowledge of intelligence education (Zhang Jinbao \& Ji Lingyan, 2018).

Comparing the development of intelligence education in foreign countries, it is found that it is mainly centered on the "Application of artificial intelligence in education" (Jia Jiyou, 2010; Zhang Kunying \& Zhang Jianian, 2018; Wang Tingting \& Ren Youqun, 2018), aiming to research into "intelligent tutoring system", "intelligent learning environment", "adaptive hypertext system", "computer-aided collaborative learning system", etc. Therefore, this paper mainly uses the keyword "AIED" to make an indepth analysis of the related research of international "intelligence education".

\section{RESEARCH STATUS OF INTERNATIONAL INTELLIGENCE EDUCATION}

This paper mainly uses bibliometrics to analyze the research status of "intelligence education" in the world.
In the "core collection" database of the international journal retrieval platform "Web of Science (WOS)", the "artificial intelligence in education" is used as the subject for retrieval. The time span is from 1998 to now. As of November 20, 2018, 864 document records have been obtained, and 387 journal articles have been obtained, excluding conference papers, reviews and other articles. Citespace can be used to analyze the research status in a certain field. Through clustering analysis of research hotspot, knowledge characteristics can be displayed in a visual form, so it is widely used as a research tool (Chen, 2006).

\section{A. Quantitative analysis on research results of international intelligence education}

First of all, in terms of the volume of documents (see "Fig. 1"), the trend basically conforms to the wave experienced by the development of "artificial intelligence". Before and after 1998, the development of the second wave of artificial intelligence was limited by the amount of data and the test environment, which made the development of related research become flat or even low, and the growth of the research on the related topics of intelligent education from 1998 to 2014 was also relatively slow. However, after 2015, it has shown an obvious upward trend. In 2015, artificial intelligence achieved a leap forward development. For the first time, the accuracy of image recognition of artificial intelligence algorithm based on deep learning exceeded that of human eyes (the Electronic Frontier Foundation, 2017). After that, human beings have made breakthroughs in voice recognition data mining, natural language processing and other fields, and more and more researchers are also focusing on the field of intelligence education.

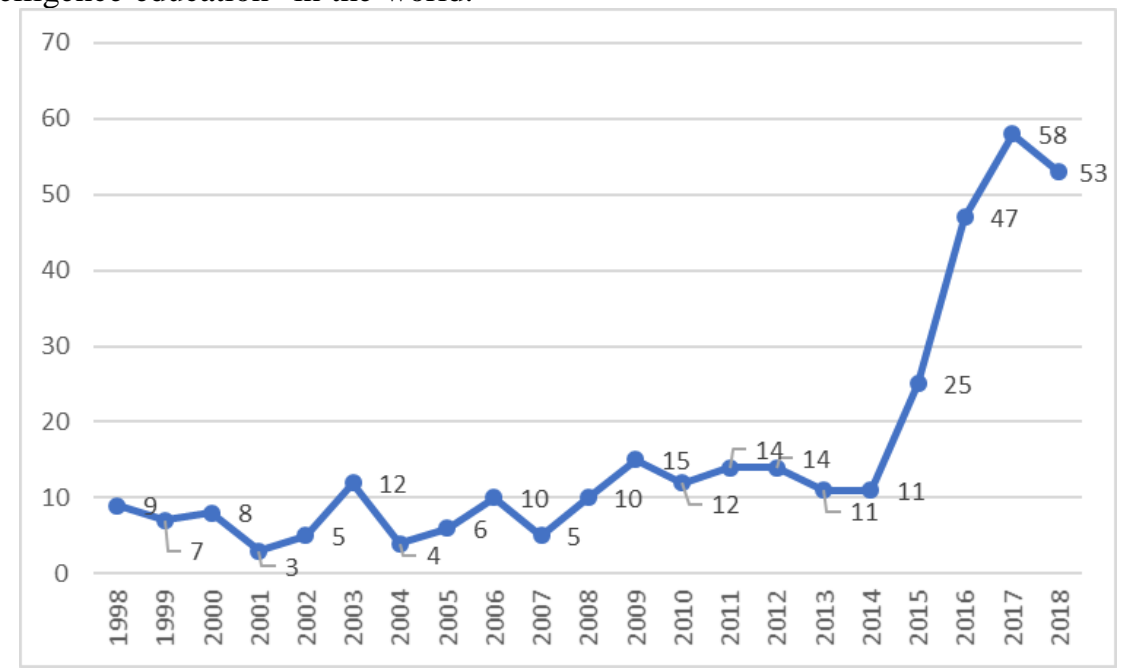

Fig. 1. Number of research documents of international intelligence education in recent 20 years. 


\section{B. Countries and research institutions of high-yield research on international intelligence education}

From the perspective of countries of high-yield research (see "Table I"), the traditional developed countries such as the United States, the United Kingdom and Spain occupy the top 10, but it is worth noting that China ranks the second in the number of research results published in international journals, and the research results of Taiwan scholars are also among the top 10, which means that China's intelligence education field is producing more and more highquality research results. At the same time, the similar situation in high-yield research institutions can be seen. International famous universities, led by the University of Georgia, Harvard University and University of London, are the main force of research. And Sagacity, a technology consulting company in the United States, also has a lot of research output in intelligence education.

TABLE I. COUNTRIES AND RESEARCH INSTITUTIONS OF HIGH-YIELD RESEARCH IN THE FIELD OF INTERNATIONAL INTELLIGENCE EDUCATION

\begin{tabular}{|l|l|l|l|}
\hline Country / Region & $\begin{array}{c}\text { The number of } \\
\text { papers }\end{array}$ & \multicolumn{1}{|c|}{ Research institutions } & $\begin{array}{c}\text { The number of } \\
\text { papers }\end{array}$ \\
\hline U.S.A & 110 & University of Georgia (United States) & 8 \\
\hline China & 34 & Harvard University (USA) & 7 \\
\hline England & 33 & University of London (UK) & 7 \\
\hline Spain & 28 & Carnegie Mellon university (USA) & 6 \\
\hline Canada & 27 & University of Granada (Spain) & 5 \\
\hline Australia & 18 & Rutgers University (USA) & 4 \\
\hline Turkey & 16 & Sagacity Company (USA) & 4 \\
\hline Brazil & 14 & Georgia Institute of Technology (USA) & 4 \\
\hline Germany & 12 & Heriot-Watt University (UK) & 4 \\
\hline Taiwan & 11 & Mcgill University (Canada) & 4 \\
\hline
\end{tabular}

\section{Highly-cited journals in the field of international intelligence education}

"Cited journal" is usually used to analyze journals with high citation rate, which also means that the journal occupies a high position in a certain field. "Table II" shows the top 10 highly-cited journals in the field of international intelligence education, mainly focusing on computer science, artificial intelligence technology, etc. Among them, the journal with highest citation rate is the conference proceedings focusing on the research of computer science and information technology, "Lecture Notes in Computer Science", which has been published since 1973 and 11207 volumes. "Computers \& Education", the SSCI journal with second citation rate, aims to expand the theoretical and practical research on how digital technologies promote education by publishing high-quality research results. At the same time, it advocates receiving highquality qualitative and quantitative research. The SCI journal "artificial intelligence", which was published in 1970, has become an internationally recognized highlevel research journal in the field of artificial intelligence, mainly focusing on artificial intelligence and philosophy, automatic reasoning and trial reasoning, heuristic search and intelligent robot and other related research. In addition to the first three highly-cited journals, the list also includes the wellknown "science" founded by Edison in 1880, which is one of the most authoritative academic journals in the world, as well as the "Nature" journal that has consistently published the most important breakthrough in the field of science and technology in the world since its inception in 1869.

Also, there are three journals in the table showing the state of "emergence", which means that the contents of these three journals about intelligence education have been quoted on a large scale in a short time, and have a high impact in the field. "International Journal of Artificial Intelligence in Education" is the official journal of the Artificial Intelligence in Education (AIED). It aims to publish papers on the application of artificial intelligence in education, and help to formulate principles of learning system design under the support of intelligent technology. From learning environment to system architecture, and from statistical methods to large artificial tools, the journal publishes different research topics from the perspective of interdisciplinary, and provides problem solutions that are intrinsically related to education and an international perspective on computer-based learning system design. Therefore, this paper analyzes the research status and progress in the field of international intelligence education from the perspective of emerging journals and article content. 
TABLE II. TOP 10 HIGHLY-CITED JOURNALS IN THE FIELD OF INTERNATIONAL INTELLIGENCE EDUCATION

\begin{tabular}{|l|l|l|}
\hline \multicolumn{1}{|c|}{ Ranking } & \multicolumn{1}{|c|}{ Highly-cited international journals } & \multicolumn{1}{|c|}{$\begin{array}{c}\text { Total number of } \\
\text { citations }\end{array}$} \\
\hline 1 & Lecture Notes in Computer Science* & 58 \\
\hline 2 & Computers \& Education & 53 \\
\hline 3 & Artificial Intelligence & 47 \\
\hline 4 & International Journal of Artificial Intelligence in Education* & 45 \\
\hline 5 & Communication of the ACM & 42 \\
\hline 6 & Expert System with Applications & 40 \\
\hline 7 & Science & 40 \\
\hline 8 & AI magazine & 30 \\
\hline 9 & Cognitive Science & 27 \\
\hline 10 & Nature* & 24 \\
\hline
\end{tabular}

\section{ANALYSIS ON RESEARCH FIELDS AND HOTSPOTS OF INTERNATIONAL INTELLIGENCE EDUCATION}

\section{A. Analysis on research fields}

Through the data analysis of WOS, it can see the distribution of research subjects focusing on international intelligence education. It can be found that "computer science", "educational research" and

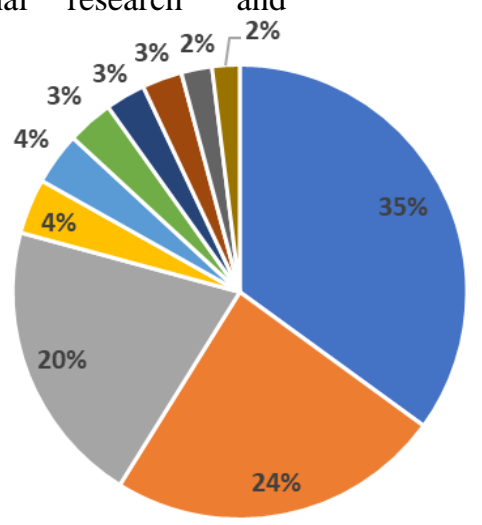

Fig. 2. Discipline distribution of international intelligence education research.

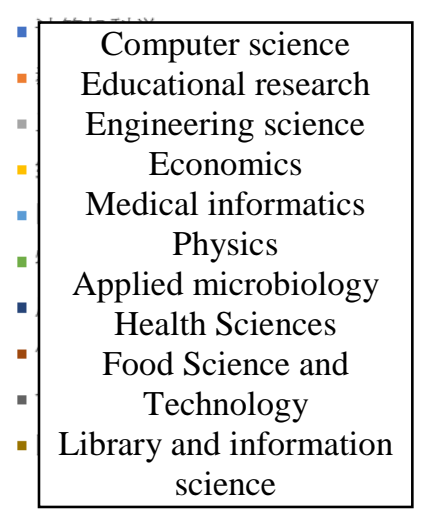

effective in four facial expression recognition data collections (Wang, Wang \& Ni, 2018). In terms of genetics, talent in cognitive development is the result of genetic variation with different effects. Some scholars have proposed neural computing models for cognitive development, using artificial neural networks to simulate the development of children's groups, and instantiating polygenic models, changes in the level of environmental stimulation, etc. The "gifted" networks at the computing level tend to have higher capacity and strong plasticity, which is verified by experiments. In the field of surgical data science, Ross et al. (2018) used automatic image annotation solutions with indepth learning. The availability of algorithm reference annotation has become a research bottleneck, proposing to use self-monitoring learning to solve this problem. 


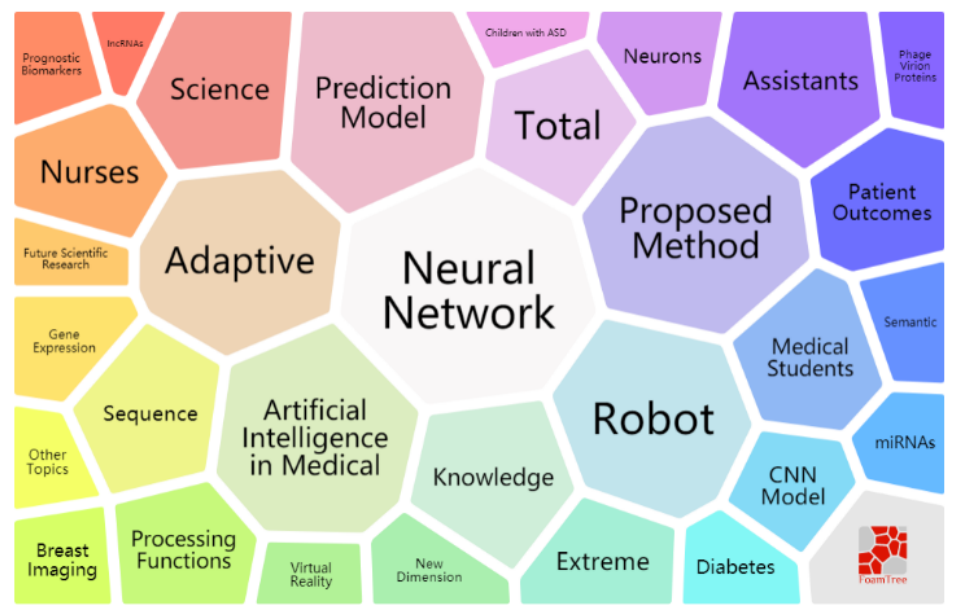

Fig. 3. Tree diagram of research hotspots in the field of international intelligence education.

\section{B. Analysis on research hotspot}

The key words of the paper reflect the theme of the paper and the research interests of the author. Therefore, the analysis of the key words can provide research hotspots and research interests of researchers in a certain field (Xie, Zhang \& Ho, 2008). Citespace is used to analyze the keyword co-occurrence network of the bibliographic data. The co-occurrence map of highfrequency key terms, that is, the map of research hotspot knowledge, is analyzed. As shown in "Fig. 4", the size and color of key words represent the importance of their position in the whole network. It is to sort the keywords in descending order. In addition to the two search keywords, research related to the "system", "model" and "design" is relatively hot, and related research topics such as "technology", "ITS (Intelligent Tutoring System)" and "E-learning" have been extended consistently.

It is worth noting that in recent three years, researchers have paid close attention to three key words: "big data", "student" and "machine learning". As early as the 1980s, the word "big data" has been known to the public, and some people attribute it to the contribution of Mashey J (1998), an American computer scientist. Today, "big data is a parallel computing tool for data processing." Mayer, V \& Cukier (2013) defined machine learning as a mode in big data: "big data usually does not ask the reason, but only test mode". Big data is characterized by $4 \mathrm{~V}$ (volume, variety, velocity and veracity). In 2011, McKinsey Global Institute described the main parts of big data as follows: data analysis technology (A / B test, machine learning and natural language processing), technical features (business intelligence, cloud computing and database), visualization (chart, graph or other display) (McKinsey Global Institute, 2011). The influence of big data in the field of education is reflected in the following aspects. The first is "digital education governance", which means that big data can provide "data visualization", "predictive analysis" and "real-time policy tools" for education, such as visualizing highly complex digital interactive data to construct knowledge of education system, tracking and predicting the performance of learners by using learning analysis platform, and using digital policy tools to demonstrate how database tools and infrastructure are at the heart of national and global governance education, governance and management (Williamson, 2015). Eynon (2013) discusses what the rise of big data means for education, technology and media research. For the field of education, big data has become a new and rapidly growing topic. Education data mining and stress analysis are becoming research identifiers. The government began to publish a report on the potential of big data education. However, considering the use of data to improve efficiency, enhance transparency and the tool to evaluate performance, it will still cause critical thinking of the public. Against the background of higher education, the implementation of big data still faces some opportunities and challenges. Data warehouse can be an effective way to release the value of big data in higher education. It provides researchers with the opportunity to conduct real-time analysis of learning activities, and create prediction models to check students at risk and provide appropriate interventions, so that teachers can adjust their teaching or conduct personalized counseling. However, the continued growth of learning analytics means that people need to consider not only the huge opportunities for better and more effective decision-making in higher education, but also the ethical challenges of institutionalizing learning analytics (Daniel, 2015). 


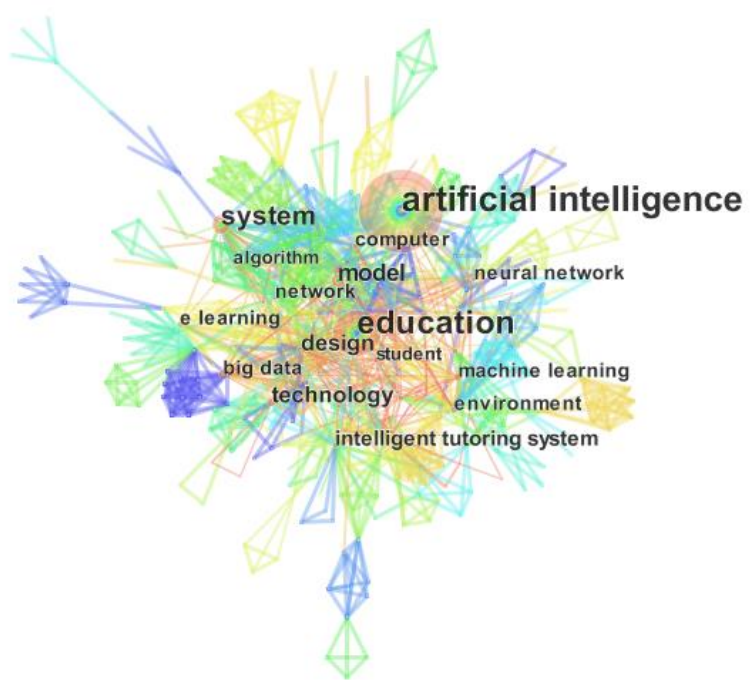

Fig. 4. Keywords co-occurrence map of international intelligence education research.

\section{CONCLUSION}

This paper systematically reviews the research status of international intelligence education and reveals the research map of international intelligence education (including the number of research results, leading countries / research institutions and highly-cited journals). Combined with the analysis on focus areas and hotspots of research keyword, three research hotspots of "big data, students and machine learning" are mined out. The purpose of this paper is to provide some reference for the development of intelligence education and the researchers who pay attention to it.

With the rapid development of artificial intelligence technology, more and more new technologies or applications will appear in the future to promote the development of educational informatization. However, in the process of the application of artificial intelligence education, there are still many factors worthy of discussion. Michael Wooldridge, an artificial intelligence researcher at the department of computer science in University of Oxford, said, "there is an obviously AI bubble at the moment. Will the bubble burst, like the Internet bubble burst from 1996 to 2001, or is it slightly deflated?" For human beings, it is a question worth thinking about. At the same time, with the development of technology, there are many challenges, such as the privacy of education data, the role transformation of teachers and students in the intelligent era, the intelligence education management of schools, and the change of teaching environment. In the face of the changes brought by artificial intelligence, education must take the initiative and adjust in time to maximize the advantages of technology, so as to realize the cultivation of pillar talents with core literacy in the new era and better serve the social economy and development.

\section{References}

[1] Wang Tingting, Ren Youqun. Talent Strategy in the Age of Artificial Intelligence:Interpretation of the "Innovative Action Plan for Artificial Intelligence in Colleges and Universities"(3) [J]. Distance Education Journal, 2018,36 (05): 52-59. (in Chinese)

[2] Zhu Zhiting, Wei Fei. Educational Informatization 2.0 : Starting on a Journey of Intelligence Education Guided by Smart Education [J]. E-education Research, 2018, 39 (09): 5-16. (in Chinese)

[3] Liu Dejian, Du Jing, Jiang Nan, Huang Ronghuai. Trends in Reshaping Education with Artificial Intelligence [J]. Open Education Research, 2018, 24 (04): 33-42. (in Chinese)

[4] Liu Kai, Hu Xiangen, Ma Yuhui, Na Di, Zhang Yuhua. The Outline of Artificial Intelligence Research in China's Education:An Artificial General Intelligence Perspective [J]. Open Education Research, 2018, 24 (02): 31-40 + 59. (in Chinese)

[5] Zhang Jinbao, Ji Lingyan. Artificial Intelligence Enhanced Education or Education for Development of Intelligence--An Analysis on Connotation and Target of Intelligent Education in the Age of Artificial Intelligence [J]. Modern Distance Education Research, 2018 (02): 14-23. (in Chinese)

[6] Jia Jiyou. Artificial Intelligence Enables Education and Learning [J]. Distance Education Journal, 2018,36 (01): 39-47. (in Chinese)

[7] Zhang Kunying, Zhang Jianian. New Areas, Misunderstandings, Blind Areas and Forbidden Areas in the Application and Research of Artificial Intelligence Education [J]. Distance Education Journal, 2017, 35 (05): 54-63. (in Chinese)

[8] Zhao Yinsheng. The inspiration of Singapore's experience in promoting intelligent education $[\mathrm{J}]$. CET China Educational Technology, 2013 (03): 29-31. (in Chinese)

[9] Ale Ebrahim, N., Salehi, H., Amin Embi, M., Habibi Tanha, F., Gholizadeh, H., Motahar, S. M., \& Ordi, A. (2013). Effective Strategies for Increasing Citation Frequency. International Education Studies, 6(11). doi:10.5539/ies.v6n11p93.

[10] Autor, David H.(2015). Why Are There Still So Many Jobs? The History and Future of Workplace Automation. Journal of Economic Perspectives, 29 (3): 3-30. 
[11] Blanchard, E. G. (2014). Socio-Cultural Imbalances in AIED Research: Investigations, Implications and Opportunities. International Journal of Artificial Intelligence in Education, 25(2):204-228. doi:10.1007/s40593-014-0027-7.

[12] Broisin, J., Venant, R., \& Vidal, P. (2015). Lab4CE: a Remote Laboratory for Computer Education. International Journal of Artificial Intelligence in Education, 27(1):154-180. doi:10.1007/s40593-0150079-3.

[13] Brusilovsky, P. (1996). Methods and techniques of adaptive hypermedia. User Modeling and User-Adapted Interaction, 6(2-3), 87-129. doi:10.1007/bf00143964.

[14] Brusilovsky, P. (2001). Adaptive Hypermedia. User Modeling and User-Adapted Interaction, 11, 87-110.

[15] Brusilovsky, P., Eklund, J., \& Schwarz, E. (1998). Webbased education for all: a tool for development adaptive courseware. Computer Networks and ISDN Systems, 30, 291-300

[16] Brynjofsson, E. (2014). The Second Machine Age. W. W. Norton \& Company.

[17] Chen, C. (2006). CiteSpace II: Detecting and visualizing emerging trends and transient patterns in scientific literature. Journal of the American Society for Information Science and Technology, 57(3):359-377. doi:10.1002/asi.20317.

[18] Clancey, W.J. (1987). Knowledge-based tutoring: the Guidon Program. Cambridge, Massachusetts: MIT Press.

[19] Conati, C., Gertner, A., \& Vanlehn, K. (2002). User Modeling and User-Adapted Interaction, 12(4):371-417. doi:10.1023/a:1021258506583.

[20] Daniel, B. (2015). Big Data and analytics in higher education: Opportunities and challenges. British Journal of Educational Technology, 46(5), 904-920. doi:10.1111/bjet.12230.

[21] DeFalco, J. A., Rowe, J. P., Paquette, L., GeorgoulasSherry, V., Brawner, K., Mott, B. W., Lester, J. C. (2017). Detecting and Addressing Frustration in a Serious Game for Military Training. International Journal of Artificial Intelligence in Education, 28(2):152-193. doi:10.1007/s40593-017-0152-1.

[22] Executive Office of the President. (2016). Preparing for the Future of Artificial Intelligence. Retrieved from https://obamawhitehouse.archives.gov/sites/default/files/ whitehouse_files/microsites/ostp/NSTC/preparing_for_th e_future_of_ai.pdf.

[23] Executive Office of the President. (2016). The National Artificial Intelligence Research and Development Strategic Plan. Retrieved from https://www.nitrd.gov/PUBS/national_ai_rd_strategic_pl an.pdf.

[24] Eynon, R. (2013). The rise of Big Data: what does it mean for education, technology, and media research?. Learning, Media and Technology, 38(3):237-240. doi:10.1080/17439884.2013.771783

[25] Fletcher, J. D., \& Sottilare, R. A. (2017). Shared Mental Models in Support of Adaptive Instruction for Teams Using the GIFT Tutoring Architecture. International Journal of Artificial Intelligence in Education, 28(2), 265-285. doi:10.1007/s40593-017-0147-y.

[26] Frey, C. B., \& Osborne, M. A. (2013). The Future of Employment: How Susceptible are Jobs to Computersation?. Technological Forecasting and Social Change 114
[27] Gerdes, A., Heeren, B., Jeuring, J., \& van Binsbergen, L. T. (2016). Ask-Elle: an Adaptable Programming Tutor for Haskell Giving Automated Feedback. International Journal of Artificial Intelligence in Education, 27(1):65100. doi:10.1007/s40593-015-0080-x.

[28] Gilbert, S. B., Slavina, A., Dorneich, M. C., Sinatra, A. M., Bonner, D., Johnston, J., Winer, E. (2017). Creating a Team Tutor Using GIFT. International Journal of Artificial Intelligence in Education, 28(2):286-313. doi:10.1007/s40593-017-0151-2.

[29] Hall, L., Tazzyman, S., Hume, C., Endrass, B., Lim, M.Y., Hofstede, G., Aylett, R. (2014). Learning to Overcome Cultural Conflict through Engaging with Intelligent Agents in Synthetic Cultures. International Journal of Artificial Intelligence in Education, 25(2):291-317. doi:10.1007/s40593-014-0031-y.

[30] Hossain, Z., Bumbacher, E., Brauneis, A., Diaz, M., Saltarelli, A., Blikstein, P., \& Riedel-Kruse, I. H. (2017). Design Guidelines and Empirical Case Study for Scaling Authentic Inquiry-based Science Learning via Open Online Courses and Interactive Biology Cloud Labs. International Journal of Artificial Intelligence in Education, 28(4):478-507. doi:10.1007/s40593-0170150-3.

[31] Howard, C., Jordan, P., Di Eugenio, B., \& Katz, S. (2015). Shifting the Load: a Peer Dialogue Agent that Encourages its Human Collaborator to Contribute More to Problem Solving. International Journal of Artificial Intelligence in Education, 27(1):101-129. doi:10.1007/s40593-015-0071-y.

[32] IBM Cooperation. (2008). A smarter planet: The next leadership agenda. Retrieved from https://www.ibm.com/ibm/cioleadershipexchange/us/en/ pdfs/SJP_Smarter_Planet.pdf.

[33] Jean, L., Wenger, E. (1991). Situated Learning. Legitimate Peripheral Participation. Cambridge: Cambridge University Press.

[34] Knight, S., Buckingham Shum, S., Ryan, P., Sándor, Á., \& Wang, X. (2016). Designing Academic Writing Analytics for Civil Law Student Self-Assessment International Journal of Artificial Intelligence in Education, 28(1):1-28. doi:10.1007/s40593-016-0121-0.

[35] Knight, W. (2017). Progress in AI isn't as Impressive as You Might Think. Retrieved from:https://www.technologyreview.com/s/609611/progress-in-ai-isnt-asimpressive-as -you-might-think/.

[36] Mashey, J. (1998). "Big Data ... and the Next Wave of InfraStress" (PDF). Slides from invited talk. Usenix. Retrieved 15 November, 2018.

[37] Mayer, R. E. (2004). Should there be a three-strikes rule against pure discovery learning? The case for guided methods of instruction. Am Psychol, 59(1) : 14-19. doi:10.1037/0003-066X.59.1.14.

[38] Mayer, R. E., \& Moreno, R. (1998). Split-attention Effect in Multimedia Learning: Evidence for Dual Processing Systems in Working Memory. Journal of Educational Psychology, 90(2): 312-320.

[39] Mayer, R. E., \& Moreno, R. (2003). Nine Ways to Reduce Cognitive Load in Multimedia Learning. Educational Psychologist, $38(1)$ : 43-52. doi:10.1207/s15326985ep3801_6.

[40] Mayer-Schönberger, V., \& Cukier, K. (2013). Big data: a revolution that will transform how we live, work and think. London: John Murray.

[41] McKinsey Global Institute. (2011). Big Data: The next frontier for innovation, competition, and productivity.Retrievedfrom.:http://www.mckinsey.com/I 
nsights/MGI/Research/Technology_and_Innovation/Big _data_The_next_frontier_for_innovation.

[42] Mohammed, P., \& Mohan, P. (2014). Dynamic Cultural Contextualization of Educational Content in Intelligent Learning Environments using ICON. International Journal of Artificial Intelligence in Education, 25(2), 249-270. doi:10.1007/s40593-014-0033-9

[43] Mostafavi, B., \& Barnes, T. (2016). Evolution of an Intelligent Deductive Logic Tutor Using Data-Driven Elements. International Journal of Artificial Intelligence in Education, 27(1):5-36. doi:10.1007/s40593-016-01121 .

[44] Nye, B. D. (2014). Intelligent Tutoring Systems by and for the Developing World: A Review of Trends and Approaches for Educational Technology in a Global Context. International Journal of Artificial Intelligence in Education, 25(2):177-203. doi:10.1007/s40593-0140028-6.

[45] Pane, J. F., Griffin, B. A., Mccaffrey, D. F., \& Karam, R. (2013). Effectiveness of cognitive tutor algebra i at scale. Educational Evaluation \& Policy Analysis, 36(2):127144.

[46] Person. (2016). Intelligence Unleashed: An argument for AI in Education. Retrieved from https://www.pearson.com/content/dam/corporate/global/ pearson-dot-com/files/innovation/IntelligenceUnleashed-Publication.pdf

[47] Perin, D., \& Lauterbach, M. (2016). Assessing TextBased Writing of Low-Skilled College Students. International Journal of Artificial Intelligence in Education, 28(1):56-78. doi:10.1007/s40593-016-0122$\mathrm{z}$.

[48] Realizing the iN2015 Vision. (2010). Retrieved from: https://www.tech.gov.sg/-/media/GovTech/Aboutus/Corporate-Publications/PDFs/iN2015-

Reports/realisingthevisionin2015.pdf.

[49] Rivers, K., \& Koedinger, K. R. (2015). Data-Driven Hint Generation in Vast Solution Spaces: a Self-Improving Python Programming Tutor. International Journal of Artificial Intelligence in Education, 27(1):37-64. doi:10.1007/s40593-015-0070-z.

[50] Roll, I., Russell, D. M., \& Gašević, D. (2018). Learning at Scale. International Journal of Artificial Intelligence in Education, 28(4):471-477. doi:10.1007/s40593-0180170-7.

[51] Ross, T., Zimmerer, D., Vemuri, A., Isensee, F., Wiesenfarth, M., Bodenstedt, S., Maier-Hein, L. (2018). Exploiting the potential of unlabeled endoscopic video data with self-supervised learning. International Journal of Computer Assisted Radiology and Surgery, 13(6), 925-933. doi:10.1007/s11548-018-1772-0.

[52] Si, M. (2015). A Virtual Space for Children to Meet and Practice Chinese. International Journal of Artificial Intelligence in Education, 25(2): 271-290. doi:10.1007/s40593-014-0035-7.

[53] Stanford University. (2016). Artificial Intelligence and Life in 2030. Retrieved from https://ai100.stanford.edu/sites/default/files/ai_100_repor t_0831fnl.pdf.

[54] Steels, L. (1990). Components of Expertise. AI Magazine. 11(11), 2, 28-49.

[55] Steenbergenhu, S., \& Cooper, H. J. J. o. E. P. (2013). A meta-analysis of the effectiveness of intelligent tutoring systems on $\mathrm{K}-12$ students' mathematical learning. Journal of Educational Psychology, 105(4):970.
[56] SteenbergenHu, Saiying, Cooper, \& Harris. (2014). A meta-analysis of the effectiveness of intelligent tutoring systems on college students' academic learning. Journal of Educational Psychology, 106(2):331-347.

[57] The Electronic Frontier Foundation. Measuring the Progress of AI Research. (2017). Retrieved from :https://www.eff.org/files/AI-progress-metrics. html\#Vision

[58] Thomas, \& Michael, S. C. (2018). A neurocomputational model of developmental trajectories of gifted children under a polygenic model: when are gifted children held back by poor environments?. Intelligence, 69, 200-212.

[59] Uchidiuno, J., Koedinger, K., Hammer, J., Yarzebinski, E., \& Ogan, A. (2017). How Do English Language Learners Interact with Different Content Types in MOOC Videos?. International Journal of Artificial Intelligence in Education, 28(4):508-527. doi:10.1007/s40593-017-0156-x.

[60] Uchidiuno, J. O., Ogan, A., Yarzebinski, E., \& Hammer, J. (2017). Going Global: Understanding English Language Learners' Student Motivation in EnglishLanguage MOOCs. International Journal of Artificial Intelligence in Education, 28(4):528-552. doi:10.1007/s40593-017-0159-7.

[61] University, W. S. (2013). How effective are pedagogical agents for learning? a meta-analytic review. Journal of Educational Computing Research, 49(1):1-39.

[62] Vajjala, S. (2017). Automated Assessment of NonNative Learner Essays: Investigating the Role of Linguistic Features. International Artificial Intelligence in Education Society, 28, 79-105. doi:10.1007/s40593017-0142-3.

[63] VanLehn, K. (2011). The Relative Effectiveness of Human Tutoring, Intelligent Tutoring Systems, and Other Tutoring Systems. Educational Psychologist, 46(4):197-221.

[64] VanLehn, K., Siler, S., Murray, C., Yamauchi, T., \& Baggett, W. B. (2003). Why Do Only Some Events Cause Learning During Human Tutoring? Cognition and Instruction, doi:10.1207/s1532690xci2103_01

[65] Wang, X., Wang, X., \& Ni, Y. (2018). Unsupervised domain adaptation for facial expression recognition using generative adversarial networks. Computational Intelligence \& Neuroscience, 10, 1-10.

[66] Wenger, E. (1998). Communities of Practice: Learning, Meaning, and Identity. Cambridge: Cambridge University Press.

[67] Wenting, M. A. , ADESOPE, Olusola, O. , John, C. , \& Liu, Q. (2014). Intelligent tutoring systems and learning outcomes: a meta-analysis. Journal of Educational Psychology, 106(4):901-918.

[68] Weston-Sementelli, J. L., Allen, L. K., \& McNamara, D. S. (2016). Comprehension and Writing Strategy Training Improves Performance on Content-Specific SourceBased Writing Tasks. International Journal of Artificial Intelligence in Education, 28(1):106-137. doi:10.1007/s40593-016-0127-7.

[69] Wiggins, J. B., Grafsgaard, J. F., Boyer, K. E., Wiebe, E. N., \& Lester, J. C. (2016). Do You Think You Can? The Influence of Student Self-Efficacy on the Effectiveness of Tutorial Dialogue for Computer Science. International Journal of Artificial Intelligence in Education, 27(1):130-153. doi:10.1007/s40593-0150091-7. 
[70] Xie, S., Zhang, J., \& Ho, Y. S. (2008). Assessment of world aerosol research trends by bibliometric analysis. Scientometrics, 77(1):113-130.

[71] Williamson, B. (2015): Digital education governance: data visualization, predictive analytics, and 'real-time' policy instruments, Journal of Education Policy. 31(2):119.

[72] Yeomans, M., Stewart, B. M., Mavon, K., Kindel, A., Tingley, D., \& Reich, J. (2017). The Civic Mission of MOOCs: Engagement across Political Differences in Online Forums. International Journal of Artificial Intelligence in Education, 28(4):553-589. doi:10.1007/s40593-017-0161-0.

[73] White, H. D., \& Mccain, K. W. (1998). Visualizing a discipline: an author co-citation analysis of information science, 1972-1995. John Wiley \& Sons, Inc.

[74] Zhou, X., \& Zhao, G. (2015). Global liposome research in the period of 1995---2014: a bibliometric analysis. Scientometrics. 105(1):231-248. 